\title{
A imag-ética do indivíduo
}

\section{The imag-ethics of the individual}

\author{
Ceres Víctora \\ Doutora em antropologia \\ ceres@victora.com.br
}

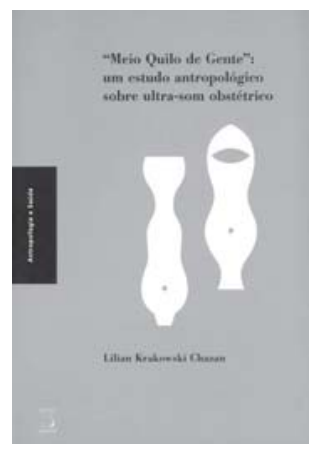

CHAZAN, Lilian K. 'Meio quilo de gente': um estudo antropológico sobre ultra-som obstétrico. Rio de Janeiro: Editora Fiocruz, 2007. $230 \mathrm{p}$.
$M$ eio quilo de gente', de Lilian Krakowski Chazan, é um estudo antropológico da mais alta qualidade sobre os usos do ultrassom obstétrico no Brasil, na contemporaneidade. Trata-se, mais particularmente, de uma etnografia realizada no Rio de Janeiro, a partir da qual a autora, que é médica, psicanalista e antropóloga, problematiza fatos considerados por muitos de nós como 'naturais', no contexto dos exames de imagem aplicados à gravidez. Questionando, entre várias coisas, a objetividade da imagem técnica, a curiosidade sobre o sexo do bebê e a 'platéia' que frequenta, com as mulheres grávidas, as salas de exames de ultrassonografia, a autora revela aspectos fundamentais sobre a sociedade e a cultura brasileiras.

Ao propor um estudo sobre a construção do feto como pessoa, Chazan filia-se à sólida tradição dos estudos, no Brasil, sobre a noção de pessoa, inaugurada por Luiz Fernando Dias Duarte (1986). Dá uma contribuição singular para esse debate ao mostrar as formas de constituição da pessoa anteriormente ao nascimento, no contexto dos exames ultrassonográficos.

Ao mesmo tempo, 'Meio quilo de gente' é um estudo sobre práticas biomédicas e sobre aquilo que elas revelam a respeito da sociedade na qual estão inseridas. Assim, pode-se dizer que também contribui para uma outra linha de debates. Ao enfocar uma prática médica de visualização interna do corpo, vai ao encontro do argumento de que a biomedicina é uma disciplina que se constitui e constrói seus objetos a partir da visualidade. Nesse sentido, alinha-se aos estudos históricos e socioantropológicos sobre a biomedicina, que compreendem que a imagem - o que sugiro se tratar, na verdade, de um composto de imagens, éticas e estéticas, ou seja, uma 'imag-ética' - é fator fundamental para o aprendizado específico de uma forma de compreender os fatos biológicos. Esses estudos apontam, basicamente, em duas direções. A primeira diz respeito ao treinamento do sentido da visão como essencial para a socialização na área da biomedicina. Esse treinamento é visto como parte do processo de transformação do estudante de medicina em médico(a), sendo o 'olhar' fundamental para a caracterização de estruturas, cores, formas, linhas; para a descrição de sentidos; e para a decodificação e a interpretação de processos de laboratório 
e de exames diagnósticos (Good, 1994). A segunda refere-se à própria visualidade como técnica de ensino e, de certo modo, de doutrinação dos sentidos nos encontros entre profissionais de saúde e pacientes. Por meio da utilização de desenhos, ilustrações e recursos gráficos, frequentemente são transmitidas informações a pacientes (Víctora, Knauth, 2001). 'Ensina-se' os 'pacientes' a sentir recorrendo-se, em grande parte, a recursos imag-éticos. Transforma-se illness em disease - na linguagem de antropólogos médicos de tradição anglosaxônica da década de 1980 - e só disease em tratamento médico.

O estudo de Lilian Chazan vai se encontrar com essas duas direções para ir além. Referese, como sugeri, a uma imag-ética, mostrando que as imagens de ultrassonografia nunca são neutras e sim historicamente informadas por éticas e estéticas. Ao sugerir, como ponto de partida, o problema da construção social do olhar e os modelos de visualidade para pensar a medicalização da vida social, em particular aplicada ao corpo da mulher, à gravidez e ao feto, a autora observa não apenas que se ensina e se aprende a 'olhar', mas como se ensina e como se aprende a 'ver'. Nesse processo, importa ressaltar o sentido 'biopolítico' que Chazan, inspirada em Jonathan Crary, atribui à transformação da visualidade que se processa desde o início do século XIX. A autora discorre sobre o processo histórico de transformação e retroalimentação de observadores e de objetos de observação e sobre a articulação entre tecnologia e cultura visual, considerando sua importância para a naturalização do escrutínio na construção de novos corpos disciplinados.

É nesse sentido que a autora faz o leitor perceber que, se por um lado, ver o corpo por dentro não pode ser considerado uma novidade, por outro o ultrassom obstétrico é um fenômeno muito mais complexo. A interatividade, por exemplo, característica da tecnologia de ultrassom, coloca em xeque os limites entre a objetividade e a subjetividade. Caracterizado pelo contato físico entre profissional e cliente, o exame de ultrassonografia é mediado pelo transdutor, que transmite imagens de um (ou mais) feto(s) e de outras estruturas de dentro para fora do corpo, projetando-as numa tela, onde podem ser vistas por quem estiver presente na sala. As imagens projetadas, por sua vez, não falam por si, mas requerem interpretação médica. É nesse contexto que a autora realiza uma rica etnografia do 'escurinho da sala de exame', registrando a interação entre profissionais e clientes na qual o processo de 'mostrar o neném' adquire valor ímpar, não diretamente vinculado a questões diagnósticas. Segundo a autora, trata-se de um evento vinculado a uma cultura visual própria do nosso tempo e um lugar que, por um lado, reforça a autoridade da imagem técnica e dos seus profissionais e, por outro, contribui para a construção do feto como pessoa. Percebe, assim, uma 'dinâmica' nesse processo. Em suas palavras: “a apropriação, por assim dizer, lúdica, do exame e a atribuição de significados insólitos partindo dessa tecnologia de imagem e mesmo das verdades médicas resultam em uma instigação ao consumo da ultrassonografia e, consequentemente, em um reforço da medicalização que nela se encontra intrínseca" (p.140).

O objetivo último do livro de Chazan é discutir a construção do feto como pessoa, tema que ela desenvolve por todo o livro, mas principalmente na parte final, enfocando a centralidade do gênero para esse constructo. A esse respeito, ressalta que, embora a determinação com segurança do sexo em exames de ultrassom só seja possível a partir da $15^{\text {a }}$ ou $16^{\text {a }}$ semana de gestação, "tanto a construção de gênero quanto a subjetivação 
generificada do feto pelos atores têm início no primeiro exame, muito antes da visualização da genitália formada do feto" (p.214). Nas linhas da sua refinada etnografia, a autora mostra que, mesmo diante das maiores imprecisões, incertezas e indecisões, o gênero e a nominação dos 'bebês' são objetos fundamentais para subjetivação e construção do feto como pessoa. Da mesma forma, o consumo constitui um pilar nessa construção: "ao adquirir objetos para o bebê, a mãe 'modela' o feto e revela quem ela própria é, seguindo a lógica contemporânea de consumo que 'a pessoa é o que ela consome'”(p.198).

A transcrição e interpretação de comentários, diálogos e extratos de diários de campo realizados durante a pesquisa ressaltam a presença do 'individualismo moderno'. Com seriedade, competência e bom humor, a autora demonstra, com o auxílio da etnografia sobre o ultrassom, que é a imag-ética do indivíduo que está informando o ponto de partida e o ponto de chegada do processo de transformação de novos sujeitos sociais e o estabelecimento de novas relações de parentesco na modernidade urbana.

\section{REFERÊNCIAS}

DUARTE, Luiz Fernando Dias.

Da vida nervosa nas classes trabalhadoras urbanas. Rio de Janeiro: Jorge Zahar. 1986.

GOOD, Byron J.

Medicine, rationality, and experience. Cambridge: Cambridge University Press.1994.
VÍCTORA, Ceres.G.; KNAUTH, D.R.

Images of the body and the reproductive system among men and women living in shantytowns in Porto Alegre, Brazil. Reproductive Health Matters, London, v.9, n.18, p.22-33. 2001. 